\title{
LA CAÍDA DE LA FECUNDIDAD \\ EN GALICIA, 1970-1995: \\ EXPLICACIONES DESDE \\ LA ECONOMÍA
}

\section{Xoaquín Fernández Leiceaga}

Universidad de Santiago de Compostela

\section{RESUMEN}

En las páginas que siguen efectuaremos una aproximación a una de las características centrales de la demografía gallega en los últimos tiempos: el desplome de la fecundidad muy por debajo del nivel de reemplazo, con la consiguiente producción de generaciones cada vez menos numerosas. En la primera parte abordamos una descripción del fenómeno, interesándonos por su ritmo, el efecto del retraso en la maternidad y las diferencias provinciales o de las áreas urbanas en relación con las rurales. En la segunda parte aplicamos aquellos elementos del análisis económico que permiten explicar esta inflexión en la evolución de la fecundidad.

\section{DESCRIPCIÓN DE LA CAÍDA DE LA FECUNDIDAD}

Galicia participa, aunque con matices, de la pauta de evolución de la fecundidad que caracteriza a los países del sur de Europa. España, Italia y Portugal habían mantenido una natalidad pujante, en términos comparativos, hasta la década de los años setenta. Entraron a continuación en un descenso abrupto que situó sus tasas de fecundidad en los niveles más bajos de los países industrializados del mundo. Tanto la rapidez de la caída como el bajo nivel alcanzado son características específicas del caso español dentro del panorama de los países desarrollados. Pero Galicia sorprende, si cabe, por la persistencia y la gravedad del descenso de la fecundidad, hasta umbrales insólitos a escala

\section{Reis}


mundial: en los últimos años para los que existe información, ya claramente por debajo de 1 hijo por mujer.

Cierto es que esta pauta es compartida con algunas otras Comunidades Autónomas próximas, pues Asturias, Cantabria, Castilla-León o el País Vasco presentan un índice sintético de fecundidad (ISF) también inferior a la unidad: en general, la España del norte muestra valores por debajo de la España del sur y los archipiélagos ${ }^{1}$. Y que la fecundidad gallega ha sido baja, con referencia a la española, desde los inicios de la transición demográfica. Al no haber, además, experimentado el baby-boom que sufrió España, entra en la fase depresiva de la fecundidad con valores particularmente bajos: 2,26 hijos por mujer en 1970 frente a los 2,86 de media española. Ambos factores pueden contribuir a contextualizar lo que sucede en Galicia pero no retiran un ápice de trascendencia a la situación: los valores actuales del ISF son inferiores a los manejados en las variantes menos optimistas de las proyecciones efectuadas recientemente (IGE, 1996); pero en ellas se contemplaba una caída significativa del volumen de población y un fuerte envejecimiento poblacional en el horizonte del año 2026.

\subsection{En los últimos veinte años se han producido en Galicia generaciones cada vez menos numerosas debido a modificaciones en el comportamiento reproductivo (tasas de fecundidad)}

En Galicia ha tenido lugar una caída muy pronunciada en el número de nacimientos durante los últimos lustros: se alcanza un máximo local en 1976, con 45.000 inscripciones, y se establece un mínimo histórico en el último año con referencias (1995), en el que esa cifra se reduce a la mitad. Desde 1978 este descenso es persistente, con una pendiente que se suaviza a partir de 1986. La comparación con la evolución general de la fecundidad española (ver Delgado Pérez, 1993; Puyol, 1997) indica un ascenso más intenso y persistente en el número de nacimientos en el período central de la década de los setenta, así como un ligero retraso en la entrada en el comienzo de la caída ${ }^{2}$. Pero cuando ésta tiene lugar la pendiente es más marcada.

Una caracterización más precisa se obtiene con el Índice Sintético de Fecundidad (ISF) ${ }^{3}$. Después de un ascenso entre 1970 y 1975, gracias a la aportación de las provincias occidentales, el ISF cae poderosamente hasta 1986 - pero sobre todo durante la pasada década - y ralentiza su ritmo de descenso a continuación, con un perfil que muestra concomitancias con la evolución de

1 Datos para 1994 (INE, 1998).

2 Si descendemos a un nivel provincial detectamos una evolución parecida a la del conjunto de Galicia. Conviene destacar tan sólo la mayor intensidad de la recuperación del período 73/78 en Pontevedra.

3 También denominado Tasa general de fecundidad y calculado como el sumatorio de las tasas específicas de fecundidad por edades, en cada momento. 


\section{GRÁFICO 1}

ISF y EMMA. Galicia, 1970-1996

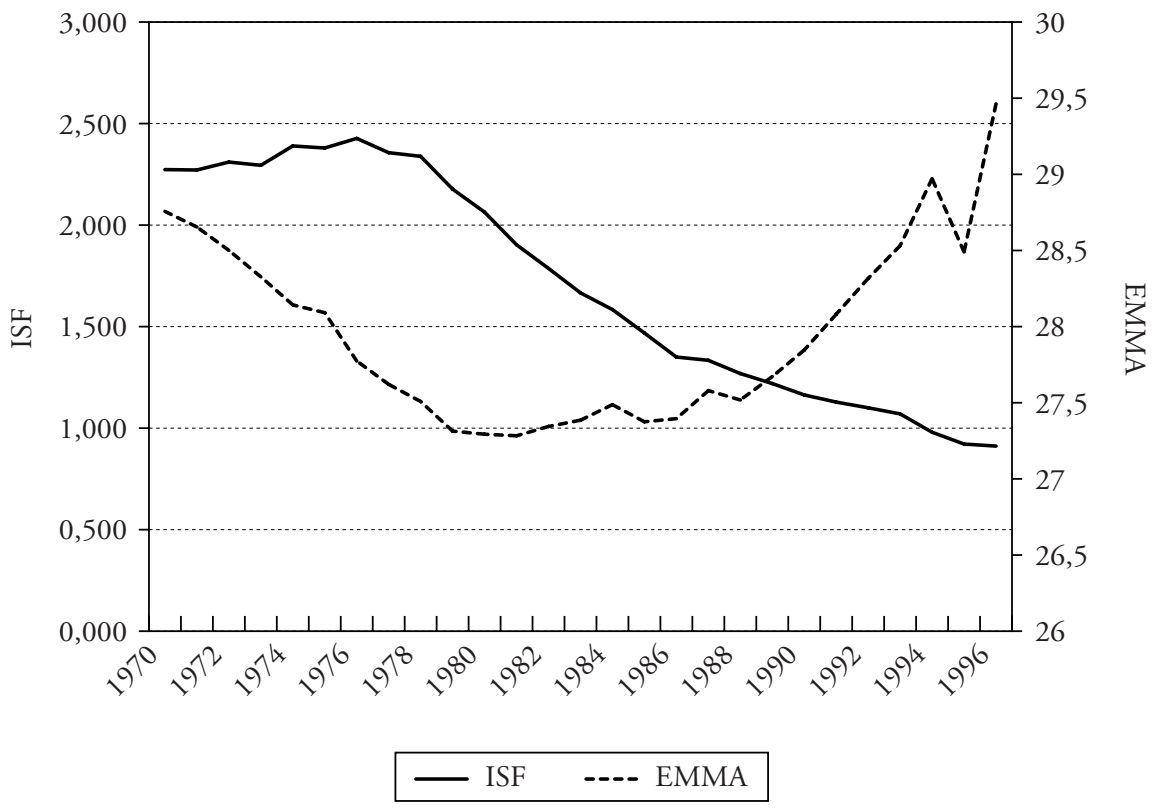

FUENTES: INE (1995); IGE. Elaboración propia. Datos provisionales para 1995 y 1996.

la coyuntura económica. Conviene destacar la nítida tendencia a la convergencia de los valores de los indicadores provinciales. En 1975 la estructura dual de los mismos era muy marcada, con las provincias occidentales por encima del nivel de reemplazo — sobre todo Pontevedra—, mientras las orientales — sobre todo Ourense- se situaban por debajo. Pero el ritmo de caída ${ }^{4}$ ha sido muy inferior en Lugo y Ourense, acortándose sensiblemente las distancias entre las cuatro demarcaciones en 1996: todas ellas presentan un ISF entre 0,8 y 1.

\subsection{Esta caida se debe en muy escasa medida al retraso en la edad media de la maternidad}

El ISF agrega cambios en la demanda efectiva de hijos con modificaciones en el calendario. Dado su carácter coyuntural, no sirve para evaluar los cam-

4 El descenso, al nivel provincial, sólo es notable y homogéneo en el período 1981/86. Entre 1975 y 1981, Lugo apenas si varía el valor del ISF; y entre 1986 y 1991, Ourense aumenta ligeramente la magnitud del mismo indicador. 
bios en la fecundidad de cada generación: un retraso de la edad media a la maternidad en una cohorte provocaría un descenso momentáneo de los valores del indicador, aunque su descendencia final no variase. Para comenzar a desentrañar esta cuestión hemos construido para cada año censal y padronal un gráfico con las tasas específicas de fecundidad por grupos de edad, descontando el efecto de la caída general de la fecundidad 5 , para Galicia.

\section{GRÁFICO 2}

Tasas especificas de fecundidad por grupos quinquenales de edad. Porcentaje sobre el total

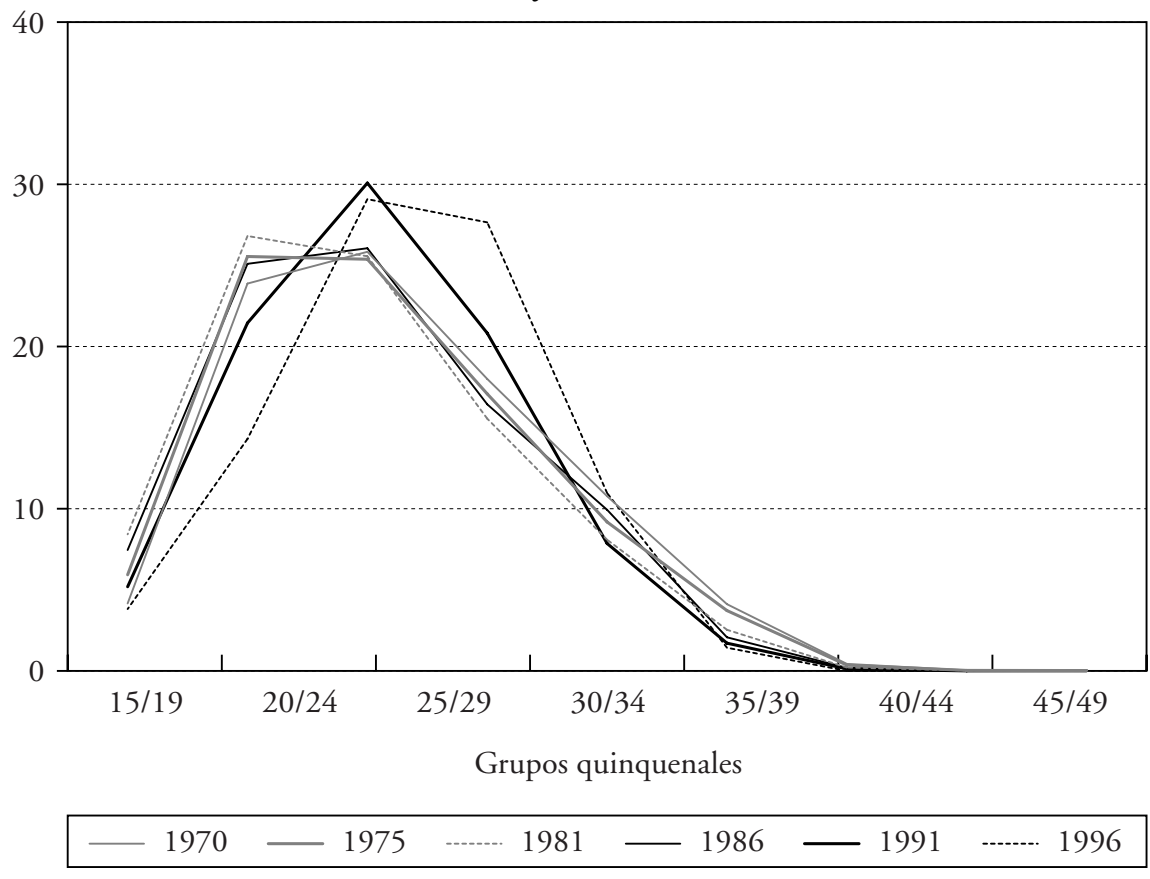

Fuentes: IGE (1987); Censo 1991; Padrón 1996. Elaboración propia.

El ligero aumento del ISF que tiene lugar hasta 1997 se liga a un ligero rejuvenecimiento, pues aumentan las proporciones de los grupos de 15/19 y 20/24 sobre la fecundidad total. Y el descenso del ISF hasta 1996 provoca una

5 Para ello representamos para cada grupo quinquenal la proporción que representa sobre el total: si el valor del Índice Sintético se modifica pero el reparto de la fecundidad entre grupos de edad permanece invariable, la forma de la curva no sufriría ninguna alteración. 
concentración de la fecundidad entre los 20 y los 34 años, pero perdiendo peso el primer grupo de edad (20/24) y ganándolo los otros dos. Esta pronunciada modificación del calendario de la fecundidad tiene lugar, sobre todo, en el período 1986/96.

Podemos reforzar estas impresiones analizando la evolución de la edad media a la maternidad (EMMA). En el año 1975 rondaba los 28 años en Galicia, cifra considerablemente inferior a la media española (28,82 años). Esta joven maternidad, en términos relativos, invierte una tendencia secular a una nupcialidad y maternidad más tardías que en España. Éste era un rasgo distintivo del modelo demográfico gallego (López Taboada, 1996): el matrimonio tardío, unido al importante celibato forzoso femenino, permitía controlar la oferta de hijos. La situación cambia en el momento en que la difusión de métodos contraconceptivos eficaces permite efectuar a bajo coste un control de los nacimientos en el seno de uniones estables. La generalización en el uso de esos nuevos mecanismos de control ha comenzado por las áreas urbanas, más desarrolladas, así como por las mujeres casadas de cierta edad ${ }^{6}$.

Entre 1970 y 1981 la EMMA cae en 0,131 años/año en Galicia, hasta situarse al final del período en 27,29 años; las diferencias interprovinciales prácticamente se anulan. El conjunto español también había experimentado un rejuvenecimiento, hasta 1981 , pero de menor intensidad, agrandándose las diferencias. Entre 1981 y 1986 apenas si se producen cambios en la EMMA (+0,01 años/año), alargándose el rejuvenecimiento en las provincias orientales y elevándose ligeramente el valor del índice en las occidentales. En España tiene lugar un ascenso, volviendo a aumentar las diferencias. La estabilidad de este índice coincide con la caída más pronunciada del ISF en Galicia, por lo que, a salvo de análisis más precisos, ambos fenómenos parecen ser independientes. Por fin, entre 1986 y 1996 se produce un fuerte ascenso de la EMMA (+0,202 años/año), más intenso en los primeros años noventa, que sitúa al indicador por encima incluso del nivel de 1970. Todas las provincias experimentan este ascenso, aunque en Lugo con menor intensidad. El retorno a la situación inicial no debe ocultar los cambios en las posiciones provinciales (atraso en las occidentales, adelanto en las orientales), que favorecen una reducción de las diferencias. $\mathrm{Ni}$ tampoco que el mantenimiento de la media es compatible con modificaciones en la intensidad de la fecundidad en cada grupo de edad: menor en las etapas iniciales y en las finales, en un movimiento compensado.

Pero si la EMMA es similar en 1975 y 1991, la evolución global del Índice Sintético de Fecundidad ha ocurrido de manera independiente de los movimientos ocurridos en la fecundidad específica por grupos de edad, que se han compensado entre sí.

¿Cómo interpretar estas variaciones conjuntas del ISF y de la $\mathrm{EMMA}^{7}$

${ }^{6}$ Muñoz Pérez (1987) detecta un comportamiento similar en España e Italia a inicios de la pasada década.

${ }^{7}$ Un cambio al alza de la EMMA provoca, caeteris paribus, una caída del ISF; y lo contrario sucede con el rejuvenecimiento de la maternidad. 
—o, más en general, de la fecundidad específica por grupos de edad—? Entre 1970 y 1975 coincide un ligero repunte del número de hijos por mujer con una caída de la edad media a la maternidad. La fecundidad aumenta ligeramente en las mujeres de menos de 24 años. Es posible, pues, que ese comportamiento alcista del ISF fuese impulsado sobre todo por la modificación del calendario, a su vez alentada por una cierta bonanza económica. Entre 1975 y 1981 se produce simultáneamente una caída del ISF y un adelanto de la EMMA. Por lo tanto, la reducción subyacente de la fecundidad es superior y de gran intensidad, pues el adelanto de la EMMA también presenta esta característica. Tiene lugar un comportamiento dispar según los grupos de edad: la fecundidad a edades avanzadas por parte de parejas de más de 25 ó 30 años (normalmente con hijos) se reduce sustancialmente, mientras que cae menos en los grupos de edad inferiores. Así, mientras que en 1975 las madres mayores de 25 años suponían el 63,9 por 100 del total, en 1981 eran tan sólo el 59,5 por $100-y$ la mayor responsabilidad en el descenso era imputable a las edades más avanzadas-.

Sin duda, la mayor facilidad en la adquisición de métodos anticonceptivos eficaces permite ajustar mejor el tamaño de la familia a los deseos de los progenitores; por otro lado, la relativa bonanza económica de que disfruta Galicia en esos años centrales de la década de los setenta ha favorecido la inserción laboral de los jóvenes, alentando el establecimiento de nuevas familias. La evolución del número de nacimientos permite sostener que este fenómeno ha jugado un papel importante hasta 1978.

Entre 1981 y 1986 coinciden un descenso muy serio del ISF y la práctica estabilidad de la EMMA. Continúa, pues, la reducción subyacente de la fecundidad a un ritmo alto, pero ligeramente atenuado en relación con el período precedente. Como ya hemos dicho, cae la fecundidad específica en todos los grupos de edad, aunque el descenso es menor entre los 25 y los 39 años. Son, sobre todo, las franjas más jóvenes y de más edad de las mujeres en período fértil las más afectadas. Esa reducción pertinaz de la fecundidad específica en los grupos de mayor edad es ya irrecuperable, provocando una descendencia menor en las cohortes afectadas.

Entre 1986 y 1996 cae el ISF con menos intensidad que en el período precedente pero se produce un retraso considerable en la EMMA. La disminución subyacente de la fecundidad se atenúa en relación con los períodos precedentes. Es ahora, como ya indicamos, cuando la concentración de los nacimientos en las mujeres de entre 25 y 35 años es más patente. En 1996 el grupo de entre 30/34 años presenta una fecundidad específica ya muy superior al grupo de entre 20/24 años, y prácticamente se iguala con el grupo de 25/29 años de edad. El 80 por 100 de la fecundidad se produce por encima de los 25 años —un porcentaje muy superior al de 1970 - , pero tan sólo un 13 por 100 tiene lugar una vez sobrepasados los 34 años (frente a un 18 por 100 en 1970).

Parece, en consecuencia, haber tenido lugar entre finales de los años setenta y mediados de los años noventa un descenso estructural en la fecundidad; 
bien es cierto que una parte del que recoge el ISF puede imputarse al retraso en las decisiones de formación de familias y tenencia de hijos que los grupos de edad más jóvenes presentan. No es posible con la información disponible prever en qué medida en los próximos años aumentará la fecundidad específica por encima de los 30 años para compensar ese retraso. Pero se puede sostener, sin miedo a errar, que las generaciones de mujeres que contaban con 25 o más años a la altura de 1975 han reducido definitivamente su fecundidad por debajo de los valores presentados por las cohortes anteriores.

\subsection{Comportamientos que tienden a homogeneizarse entre la Galicia urbana y no urbana, asi como entre las distintas ciudades}

Una de las divisiones de superior calado en el análisis de los comportamientos reproductivos es la que distingue entre áreas urbanas y rurales. La existencia de condiciones económico-sociales diversas podría afectar, a través de algún factor importante (coste de oportunidad del trabajo femenino, utilidad de los hijos, estabilidad de las rentas, etc.), a la fecundidad particular de cada área, así como a sus variaciones en el tiempo. Sin embargo, como veremos, se produce un convergencia de comportamientos.

\section{CUADRO 1}

Tasa global de fecundidad. Galicia urbana y no urbana

\begin{tabular}{|c|c|c|c|c|c|}
\hline & 1970 & 1975 & 1981 & 1986 & 1991 \\
\hline 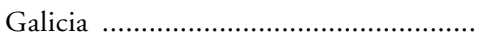 & 65,11 & 67,3 & 57,69 & 41,32 & 33,98 \\
\hline 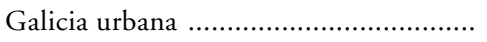 & 83,8 & 84,6 & 59,3 & 41,4 & 32,6 \\
\hline Galicia no urbana & 56,5 & 58,3 & 53,5 & 38,6 & 34,27 \\
\hline
\end{tabular}

FUENTE: A. López (1995). Elaboración propia.

En 1970 la Tasa Global de Fecundidad (TGF) era sensiblemente superior en el mundo urbano que en el rural en Galicia ${ }^{8}$, con una diferencia de 1,5. Entre 1970 y 1975 las diferencias se mantienen, con un ligero ascenso en ambas zonas. En la segunda mitad de la década de los setenta la fuerte caída en el índice general se manifiesta de forma mucho más aguda en las ciudades, de

8 Siendo urbana la población de los municipios de las siete ciudades de Galicia, y rural el resto de la población de Galicia. Cada ciudad presenta una población urbana superior a 50.000 habitantes; en conjunto, suman cerca de 1 millón de habitantes sobre una población de 2,75 millones. 
forma que las distancias se reducen $(1,1)$. Si bien hasta 1986 las posiciones relativas se mantienen, en la segunda mitad de la pasada década la TGF rural supera ya a la TGF urbana.

\section{GRÁFICO 3}

Fecundidad especifica por edad. Galicia urbana y no urbana, 1991

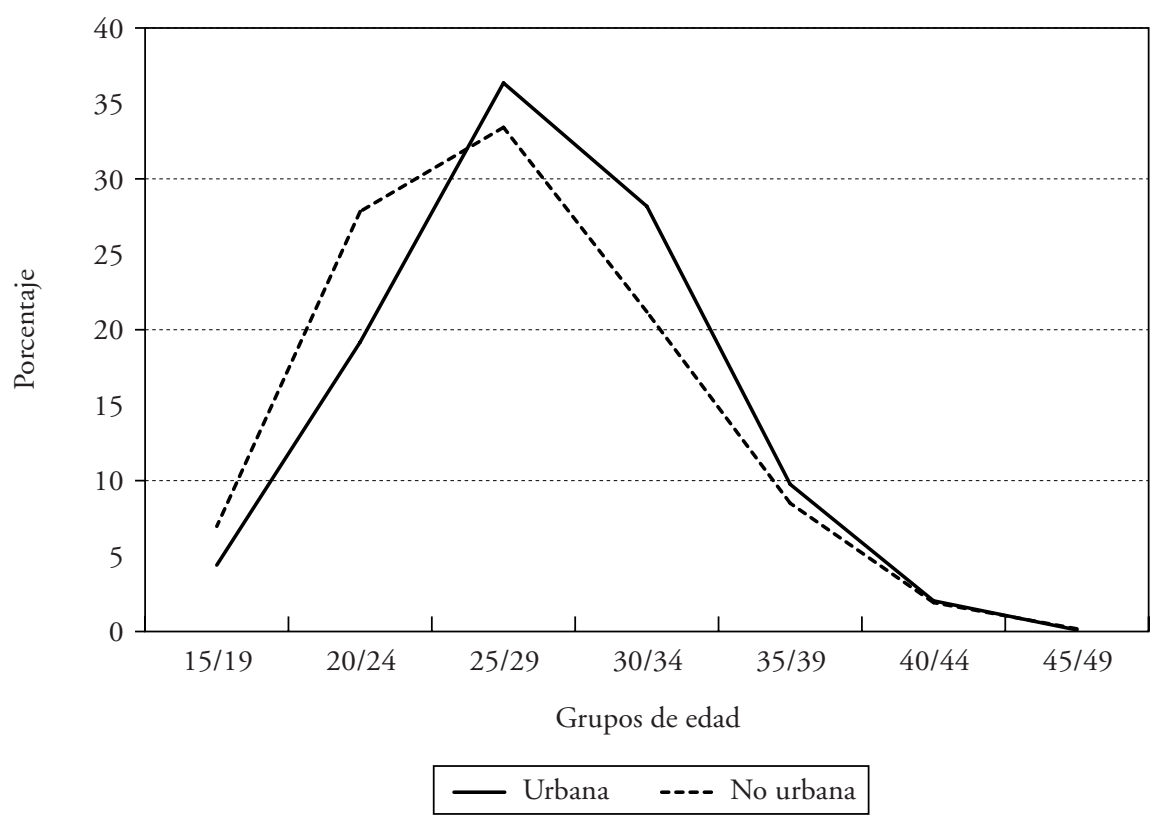

Pero como la TGF es muy sensible a la estructura por edades de la población femenina fértil, hemos elaborado un índice (Estructura de las mujeres en edad fértil) definido como la relación de las mujeres de entre 20/34 años con las mujeres de entre 15/19 más las mujeres de entre 35/49. Un ascenso de los valores del índice refleja una superior proporción de mujeres en las edades en que la fecundidad específica tiende a ser más elevada: sin cambios en la fecundidad por edades, ese ascenso provocaría una elevación de la TGF.

Pues bien, el EMEF rural muestra un crecimiento continuado desde 1975, muy acentuado desde 1981: desde un valor de 0,72 se sitúa en 0,85 dieciséis años más tarde. Por el contrario, el EMEF urbano, que también sigue una senda ascendente en la segunda mitad de los setenta, resbala suavemente a continuación. En el conjunto del período pasa de un valor 0,80 a un valor 0,76 . 
Esta evolución confirma la importancia que las variaciones en la estructura de edad de las mujeres fértiles en ambos ámbitos poseen en la modificación de la posición relativa de la TGF. Cuando la EMEF rural es más baja, la TGF también lo es. Los cambios en los valores relativos de la EMEF rural en relación con la urbana coinciden con los cambios en la TGF. Por fin, cuando, como en 1991, el EMEF rural supera al urbano, también lo hace la TGF9.

El gráfico 3 permite constatar una diferencia de cierta trascendencia en el comportamiento reproductivo de ambas áreas. En 1991 la fecundidad es considerablemente más precoz en el mundo no urbano. La proporción que representan los dos primeros grupos de edad es muy superior fuera de las ciudades, mientras que es muy inferior entre los 25 y los 34 años. Se invierten las posiciones de los grupos de entre 20/24 y 30/34 años en las zonas urbana y no urbana. Sin embargo, para ambos grupos el eje de la fecundidad se sitúa entre los 25 y los 29 años $^{10}$.

Por último, en esta descripción apresurada de la evolución de la fecundidad tiene interés conocer en qué medida existen coincidencias o divergencias entre las siete ciudades de Galicia.

En el año 1975 la concentración de los valores de la TGF es extrema: entre el nivel 80 y el 90 se sitúan seis urbes, con la franja superior compartida por Ferrol, Pontevedra, Vigo y Santiago. Sólo el ínfimo valor de Lugo (70) perturba esa coincidencia. En la segunda mitad de los setenta se reduce el grado de concentración, apareciendo Pontevedra y Santiago destacadas en cabeza, para aumentar de nuevo considerablemente a continuación, en un contexto de caída generalizada de la TGF urbana. Por fin, entre 1986 y 1991 reducen de manera sensible su TGF Ferrol y Santiago, mientras que Ourense presenta una pendiente casi nula. Pontevedra destaca por su valor elevado, que contrasta con los de Ferrol y A Coruña.

También a este nivel de superior desagregación la EMEF juega un papel relevante a la hora de explicar el nivel relativo de la TGF de cada ciudad (y sus cambios); aunque, por supuesto, no sirve para explicar la caída generalizada de la fecundidad en el medio urbano. En 1975 la EMEF más baja correspondía a Lugo, y en las posiciones de cabeza destacaban Santiago, A Coruña y Vigo. En la segunda mitad de los setenta, Santiago, Pontevedra y Lugo protagonizan los

9 Conviene precisar, sin embargo, que el EMEF gallego asciende, aunque sea suavemente, en el período 1975/1991, coincidiendo con el descenso de la TFG o del ISF. Cae, pues, decisivamente la fecundidad por más que aumente la proporción de las mujeres en la edad más fecunda sobre el total de mujeres en edad fértil, y por más que la fecundidad se concentre justamente en esos años centrales del período fértil.

${ }_{10}$ Para calcular los valores reflejados en el gráfico 3 hemos partido de los datos correspondientes al Censo de 1991 para el número de mujeres en cada grupo quinquenal de edad. Estos valores se han calculado para las siete ciudades gallegas, el resto del territorio y el conjunto de Galicia. A partir de los datos de nacimientos por grupos de edad distribuidos a nivel municipal hemos calculado la fecundidad por edad en cada espacio, así como en el conjunto de Galicia. En el gráfico, de nuevo, se representan los porcentajes de cada grupo de edad sobre el total para cada espacio y para el conjunto. 
mayores ascensos; entre 1981 y 1986 cabe destacar sobre todo la continuidad en la mejora del índice de Lugo. En el último período caen Santiago, Ferrol y Pontevedra, y ascienden Lugo y Ourense. En el conjunto del período, la Galicia urbana en su conjunto apenas si manifiesta cambios en la estructura por edades de las mujeres fértiles; pero mientras Lugo, Ourense y Pontevedra elevan el porcentaje de mujeres en la edad más fecunda, las demás (y sobre todo A Coruña) la reducen.

Existen también diferencias en el calendario reproductivo según las ciudades: más precoz (grupo de 20/24 años) en Lugo y Ourense, con un perfil próximo al de la Galicia no urbana; extremadamente concentrado en Ferrol en el grupo de edad 25/29 años, que aporta más del 40 por 100 del total; muy retrasado en Santiago, con más de un 35 por 100 de la fecundidad en el grupo de 30/34 años (y sobre el 50 por 100 por encima de los 30 años).

\subsection{La caida de la fecundidad coincide con una democratización de la misma ${ }^{11}$}

La evolución de la fecundidad debe medirse no sólo en términos coyunturales, sino también como descendencia final de las generaciones. Utilizando la información censal podemos reconstruir, sacrificando algo la precisión, la fecundidad de las cohortes, por grupos quinquenales de edad. Calculamos así el número de hijos nacidos vivos para las mujeres casadas o que lo han estado, de entre 40/44 años, entre 1970 y 1991. El valor del índice desciende desde 2,64 a 2,29. Sin embargo, la extrapolación de este resultado a la fecundidad generacional está afectada por las tasas de celibato y fecundidad extramatrimonial. En ese período la soltería femenina en ese grupo se reduce a la mitad y la fecundidad extramatrimonial cae ligeramente ${ }^{12}$. Por esa razón es necesario calcular el número de hijos nacidos vivos por mujer de cada grupo de edad ${ }^{13}$. En todos los grupos se supera el nivel de reemplazo, con un máximo para la generación de entre 50/54 años y un mínimo para la de 40/44. A pesar de este últi-

11 Por democratización entendemos una proporción superior de mujeres en cada generación con descendencia. El esfuerzo reproductivo de cada generación femenina está menos desigualmente repartido que antes.

12 La soltería, de un 17,3 a un 8,65 por 100; las mujeres solteras de 60/64 años declaraban, en 1991, 0,4 hijos nacidos vivos de media; pero, en esa misma fecha, las de 40/44 años tan sólo 0,3 . Sin embargo, utilizando datos contemporáneos procedentes del MNP, se puede indicar que el porcentaje de nacimientos protagonizados por madres no casadas ha aumentado considerablemente desde 1981 hasta la actualidad, estabilizándose en torno al 10\%. Este comportamiento, similar al español, es característico de las generaciones de mujeres de menos de 40 años en 1991.

${ }_{13}$ Utilizamos información del Censo de población de 1991 (INE) sobre el número de hijos nacidos vivos por grupos de edad para mujeres residentes en viviendas. Este cálculo no puede tomarse como una sustitución precisa de la tasa de reproducción, pues hacemos abstracción de la mortalidad femenina. Como lo que interesa es la comparación intertemporal, esta consideración no afecta gravemente a los resultados, aunque podría producirse una leve sobreestimación de las mujeres sin hijos a edades avanzadas a consecuencia de la relación directa entre partos y mortalidad femenina. 
mo descenso, las mujeres que entran en la última fase del período reproductivo a principios de los noventa mantienen una tasa de reemplazamiento ligeramente superior a la unidad y sólo levemente por debajo de la tendencia histórica. La mejora en la mortalidad infanto-juvenil y los nacimientos por llegar para esta cohorte permitirían ajustar aún más las diferencias.

\section{GRÁFICO 4}

Descendencia por cohortes, 1991

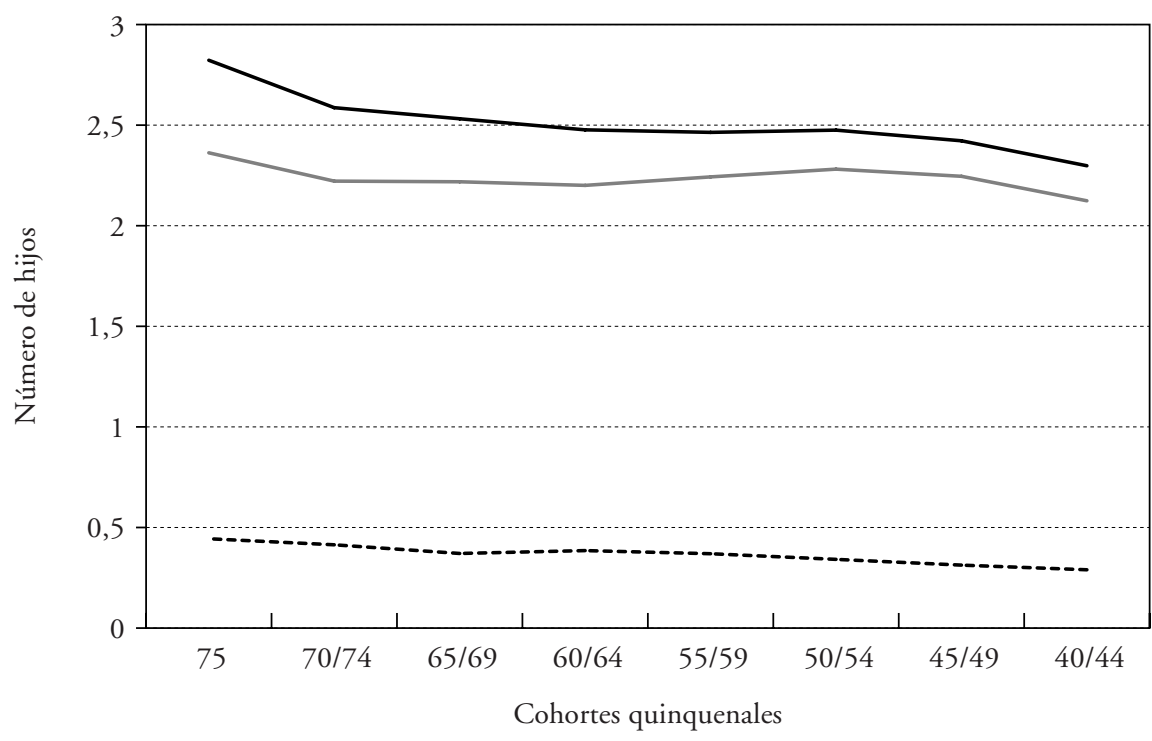

- No solteras ---- Solteras - Total

FUENTE: Censo de 1991. Elaboración propia.

Llama la atención, además, la democratización de la descendencia. El retroceso del celibato más que compensa la caída de la fecundidad externa al matrimonio. La proporción de mujeres que al llegar a los 40 años no había experimentado la maternidad se reduce a la mitad en treinta años. Al tiempo, la descendencia se concentra en torno a los $2 / 3$ hijos: un 46,55 por 100 de las mujeres (40/44 años) no solteras en 1970 y un 62,91 por 100 en 1991 . Pero este resultado se logra tanto a costa de las familias numerosas como de las que no tienen hijos. Las condiciones económicas y de difusión del control de la natalidad han sido más favorables en las últimas décadas al ajuste de la dimensión de las familias a los deseos de los progenitores. 


\section{GRÁFICO 5}

\section{Mujeres por número de hijos}

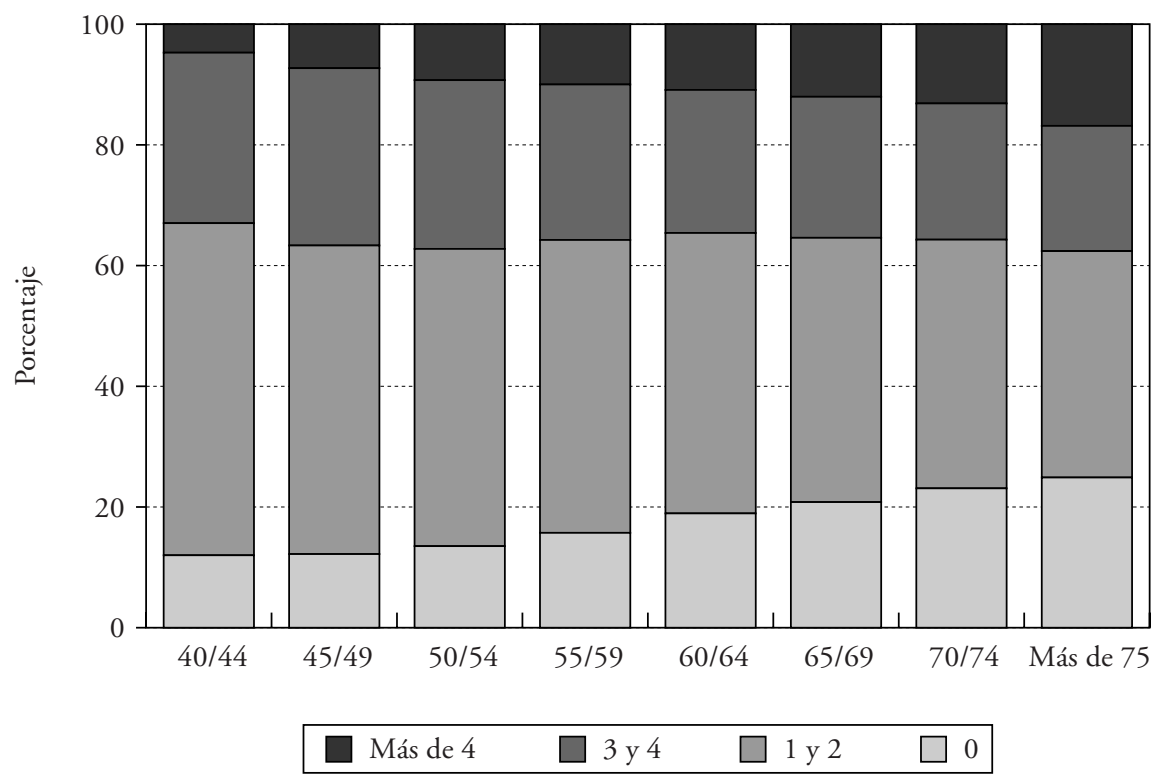

Fuente: Censo de 1991. Elaboración propia.

En cambio, el cálculo de la fecundidad acumulada por las mujeres de entre 30 y 39 años indica la dificultad de que superen el nivel de reemplazamiento. La caída de la fecundidad se concentra en las generaciones nacidas en la década de los cincuenta: son aquellas mujeres que deberían haberse incorporado al mercado de trabajo en la pasada década.

Tiene lugar, pues, un reforzamiento de la fecundidad matrimonial y una expansión de esta figura en la sociedad, lo que contrasta vivamente con la hipótesis de ruptura de la familia. La fecundidad extramatrimonial ha avanzado en los últimos años, al igual que en España, pero este comportamiento ha sido protagonizado por las generaciones más jóvenes de mujeres. Además, las prácticas maltusianas clásicas han sido sustituidas por el control de la natalidad en el interior del matrimonio. 


\section{UNA APROXIMACIÓN DESDE LA ECONOMÍA A LAS CAUSAS DE LA CAÍDA DE LA FECUNDIDAD EN GALICIA}

\subsection{Una visión económica}

Las cuestiones relativas a la oferta no deseada de hijos son marginales en nuestro entorno, lo que nos conduce a enfatizar la perspectiva de la demanda: la fecundidad es el resultado de una decisión consciente (Robinson, 1997) por parte de los individuos o las familias. Olvidamos así las restricciones biológicas o el posible efecto del coste de no tener hijos (medidas anticonceptivas de diverso tipo). Las parejas tienen la descendencia final que se acomoda a sus deseos, dadas las restricciones existentes.

Trataremos la demanda de los servicios que prestan los hijos como el resultado de la comparación del valor actual de los beneficios y costes a ellos asociados por parte de las familias, dadas las restricciones de tiempo y recursos de que disponen, así como de sus expectativas hacia el futuro. Los servicios prestados por los hijos compiten con otros posibles destinos del tiempo y la renta de las familias: el hogar maximiza su utilidad total usando los recursos totales disponibles de forma que iguala la utilidad, por unidad de recurso gastado, recibida en el margen de los variados bienes y servicios consumidos (Robinson, 1997). Adicionalmente, los hijos serían un bien normal, por lo que un incremento de la renta daría lugar a un aumento de la demanda de servicios filiales ${ }^{14}$.

¿Cuáles son estos costes y beneficios? Los costes están asociados a la tecnología de producción y mantenimiento de hijos por parte de las familias; tecnología que combina necesariamente el tiempo empleado por la madre $-\mathrm{y}$ normalmente también el padre, aunque asumimos que con menor intensidad- con bienes y servicios adquiridos en el mercado. Cada combinación de este tipo es una tecnología determinada, que cambiará en función del precio de cada uno de los factores de producción utilizados, así como de las características del bien a producir. Los costes pueden ser monetarios o no monetarios. Los primeros incluyen el coste de los bienes y servicios de mercado, así como las transferencias monetarias en dirección a los hijos. Los segundos, el coste del tiempo gastado por los padres en el cuidado de los hijos, medido por su coste de oportunidad en términos de salario de mercado. Son más relevantes los maternos, tanto por razones biológicas (embarazo, parto y lactancia, etc.) como sociales —en parte ocasionadas por la especialización derivada de las restricciones biológicas-.

Los beneficios, a su vez, están constituidos por los servicios prestados por los hijos a los padres a lo largo de su vida. Siguiendo a Leibenstein (1975), podemos diferenciar tres tipos:

14 Sin embargo, sabemos que esto no ha sucedido a lo largo del tiempo en el mundo occidental: los incrementos sostenidos en la renta han coincidido con un tránsito desde un régimen demográfico de alta fecundidad a otro de baja fecundidad. Tampoco sucede en Galicia, ni a lo largo de este siglo ni en los últimos veinticinco años, en que tiene lugar un inusitado incremento de la renta por habitante al tiempo que la fecundidad se desploma. Pero ello no es óbice para que en cada momento del tiempo la fecundidad y el nivel de renta estén correlacionados inversamente. 
1) Servicios de trabajo: aporte de trabajo por parte de los hijos a la explotación familiar o en el mercado.

2) Aseguramiento de la vejez de los padres: puede adoptar la forma de ayuda en tiempo o en dinero una vez que los padres presentan limitaciones ligadas al envejecimiento.

3) Servicios puramente de consumo: emotivos, psíquicos o de otro tipo.

Utilizando el sencillo esquema señalado en los párrafos anteriores, intentaremos explicar la caída de la fecundidad en Galicia y algunas de las características que hemos descubierto asociadas a la misma.

\subsection{Los costes de oportunidad del tiempo femenino han aumentado considerablemente en los últimos años}

La nueva mujer — tal y como la ha denominado Easterlin (1987) para someter a crítica la hipótesis de partida - tendrá una fecundidad menor que su predecesora, la mujer tradicional, por cuanto la tenencia y crianza de hijos es muy intensiva en tiempo de trabajo femenino; compite así esta actividad con el desarrollo de una carrera profesional y, sobre todo, el precio relativo de los hijos aumenta conforme el salario medio de las mujeres en edad de procrear se hace más alto. Por otra parte, como recuerda Keyfitz (1987), se puede haber producido un cambio en las preferencias de las mujeres en favor del trabajo externo frente al doméstico: el ascenso de las actividades de servicios facilita la realización de un trabajo poco fatigoso, en un medio agradable que permite la relación personal. Además, el cambio en la inserción social de la mujer ha debido modificar el conjunto de sus aspiraciones en detrimento del bien de consumo hijos. El coste de oportunidad en términos de utilidad dineraria y no dineraria de la procreación y crianza se eleva así considerablemente. Si esta hipótesis es correcta, ha de detectarse una tasa de actividad femenina en franco ascenso, con salarios cada vez más elevados.

La tasa de actividad femenina por grupos de edad presenta en 1970 un perfil tradicional. Los niveles más elevados (entre el 30 y el 40 por 100) se obtienen antes de la edad estándar del matrimonio: el máximo absoluto aparece en el grupo de 20/24 años. A continuación cae hasta niveles ligeramente inferiores al 30 por 100 , que se mantienen de manera incansable hasta los 60/64 años. La curva concluye con un abrupto descenso a partir de esa edad. El perfil apenas si acusa el impacto del cierre del período reproductivo de la mujer ${ }^{15}$. Por otro lado, la tasa de actividad femenina alcanza valores siempre muy inferiores a los masculinos.

15 Quizá la infraestimación de la tasa de actividad femenina por los distintos Censos —en comparación, por ejemplo, con la EPA (ver IGE, 1991: 24) - se concentre en estos grupos de edad, por lo que sí tendría lugar una reincorporación de la mujer a la actividad aunque la curva no lo mostrase. 
El matrimonio está ligado inicialmente a una retirada del mercado de trabajo; pero la mujer casada retorna a la actividad laboral por encima de los 30 años. Así, la tasa de actividad de las célibes está permanentemente por encima de las casadas, a diferencia de lo que sucede con los varones, pero así como estas últimas muestran un perfil ascendente hasta los 45/49 años, en las primeras descienden los porcentajes a partir de los 20/24 años. Estas cifras están afectadas por el trasvase entre los dos grupos, que tiene lugar sobre todo en la tercera década de la vida de la mujer.

La situación en 1991 es bien diferente. Lo más destacable es la notable aproximación de la tasa de actividad femenina a la masculina; son activas más de 4 mujeres de cada 10 entre los 20 y los 44 años, y más de 5 de cada 10 entre los 25 y los 35 . Además, el máximo nivel de actividad se retrasa hasta los 25/29 años. A continuación el descenso es ininterrumpido, siendo apenas perceptible el impacto de la reincorporación de la mujer a la actividad una vez acabada la etapa dedicada al cuidado de los hijos. Podría ser que en un mercado de trabajo de extrema atonía las mujeres mayores de 40 años tengan extremas dificultades para conseguir una incorporación exitosa al competir con jóvenes presumiblemente mejor formadas, en media, por puestos de trabajo muy escasos. Además, la incorporación creciente a la actividad tiene un contenido generacional marcado, de manera que está siendo protagonizada cada vez más por las cohortes más jóvenes. De ser así (ver, para el caso español, Blanes, Gil y Pérez, 1996: 136), la curva seguirá ascendiendo progresivamente, pero comenzando siempre por su lado izquierdo.

El comportamiento de las mujeres célibes se hace similar al de los varones solteros, aunque algo por debajo. Pero también la tasa de actividad de las casadas se eleva considerablemente. Si bien las curvas de las mujeres solteras y no solteras alcanzan un máximo en el mismo grupo de edad (30/34 años), no sucede lo mismo con el perfil del conjunto de mujeres. El cambio de estado civil de las mujeres solteras ya activas permite influir al alza sobre la actividad de las casadas, pero el efecto es limitado tanto en intensidad (muchas mujeres abandonan la actividad al contraer matrimonio) como en el tiempo (y algunas que siguen ligadas al mercado de trabajo lo abandonan después, posiblemente coincidiendo con el nacimiento de los hijos).

Por lo tanto, en estos veinte años se produce la parcial sustitución de una economía con una división sexual del trabajo tradicional por otra en la que las mujeres desean incorporarse al mercado laboral extrahogareño. Son precisas dos consideraciones adicionales.

La primera hace referencia al capital humano acumulado por estas generaciones de mujeres jóvenes. El nivel formativo sirve como variable proxy del salario. En el grupo de mujeres que tenían entre 50/59 años en $1991^{16}$, un 7,8 por 100 no había realizado estudios y el número medio de años de escolaridad

${ }^{16}$ Que tenían entre 29 y 38 años en 1970. 
era de 5,6; en las mujeres menores de 30 años, tan sólo el 0,2 por 100 no había cursado algún estudio y la media de años de escolaridad acumulados era de 9,9. Debemos tener en cuenta que una parte considerable de esa población está aún en período formativo, con lo que las distancias se ampliarán en el inmediato futuro ${ }^{17}$. En este último grupo el capital humano medio supera ya al del contingente masculino de igual edad. El esfuerzo formativo de las mujeres es mayor y más exitoso que el de los varones por debajo de los 35 años, medido en niveles de escolarización superados.

No sólo el coste de oportunidad del tiempo de la mujer debería aumentar como consecuencia de la acumulación de capital humano, sino que también se elevará su propensión a la actividad. Si las mujeres activas eran el 47,1 por 100 del total en Galicia en 1991, el porcentaje subía hasta las proximidades del 80 por 100 para las tituladas universitarias de ciclo largo, así como para las que habían obtenido un diploma de Formación Profesional de segundo grado (ver Palafox, Mora y Pérez, 1995: 108). El sobreesfuerzo educativo de las mujeres es síntoma de su creciente vocación a la autonomía profesional y se explica por la necesidad de compensar las desventajas derivadas de la biología, los prejuicios sociales y la menor experiencia laboral acumulada (ver Fernández Méndez de Andes, 1993). Pero amenaza con socavar las bases económicas (Becker, 1987) de la especialización tradicional en el seno del hogar: a pesar de la carga biológica de la maternidad, puede resultar racional la especialización extrahogareña de la mujer debido a su superior disposición de capital humano. Y, por lo tanto, que sea el varón el que se especialice en las tareas del hogar.

La segunda remite al fenómeno del desempleo, protagonizado de forma creciente por los jóvenes adultos de ambos sexos. En el gráfico podemos observar no sólo los elevados niveles alcanzados por el paro femenino antes de los 25 años — con un cierto componente anticíclico-, sino también su tendencia al ascenso a lo largo de la década de los ochenta — algo que sucede también para las mujeres adultas de mayor edad-. Pero así como en este caso coincide con un aceptable comportamiento de las tasas de ocupación, no sucede lo mismo antes de los 25 años: la dimensión negativa del paro juvenil femenino se agranda. No podemos, utilizando la fuente EPA, desagregar por grupos quinquenales las variables paro y ocupación femeninas a partir de los 25 años. No obstante, el Censo de 1991 indica que tan sólo por encima de los 40 cae el desempleo femenino por debajo del 15 por 100.

En una primera interpretación, el paro femenino tendería a reducir el coste de oportunidad efectivo del tiempo de la mujer, alentando así la fecundidad. Cabe efectuar dos objeciones a esta línea argumental. Una, que la decisión de tener hijos está mediatizada por la obtención de una fuente estable de ingresos que, en ausencia de una inserción laboral viable, tan sólo podría proceder del matrimonio; pero el déficit de empleos también afecta a los jóvenes varones,

17 Datos procedentes de Encuesta Socio-Demográfica 1991. Tomo III: Resultados por Comunidades Autónomas. Galicia, INE, Madrid, 1994, p. 390. 
como veremos. Además, buena parte de los empleos de que disponen los jóvenes de ambos sexos son precarios o inestables (ver infra). En este contexto, la inversión en capital humano deviene una estrategia de creciente atractivo, pues el coste de oportunidad del tiempo empleado es bajo, los costes directos asociados a la prolongación de los estudios caen por efecto de la descentralización de la oferta y, sobre todo, porque mejoran las condiciones en que se afronta la cerrada competencia en el mercado de trabajo. La difusión de esta estrategia obliga a los demás a practicarla, para no quedar completamente excluidos de la competencia por el escaso empleo generado.

Ese prolongado esfuerzo formativo altera de manera inevitable las aspiraciones de los y las jóvenes, al igual que sucede con la inserción laboral de la mujer, que modifica el conjunto de sus aspiraciones. La renta minima de paternidad ${ }^{18}$ se eleva. El coste de los servicios filiales ha aumentado a causa de la correlación directa entre formación y salario; pero también porque, con un grado de altruismo estable, cabe suponer que los progenitores deseen garantizar a sus descendientes un nivel de vida, bienestar y formación cuando menos similares a sus aspiraciones. La experiencia de un empleo tardío eleva, además, las expectativas de una superior duración de las transferencias paternofiliales.

La segunda objeción señala que la persistencia de desequilibrios en el mercado de trabajo eleva el coste, en términos de carrera profesional, del tiempo dedicado a la maternidad. Dada la voluntad de una proporción creciente de mujeres de incorporarse a ocupaciones remuneradas extradomésticas, la tenencia y el cuidado de los hijos es un grave impedimento, bien porque compite con una estrategia de inversión en capital humano, bien porque la posibilidad de recuperar un empleo después de una retirada temporal es baja. La caída de las tasas de actividad de las mujeres casadas por encima de los 35 años, sin ulterior recuperación, sería indicativa de la dificultad de reanudar el trabajo externo más que del deseo de permanecer en el hogar. Ya hemos analizado la evolución de las tasas de actividad femeninas; si observamos ahora la proporción de mujeres dedicadas a labores del hogar comprobamos que se produce un descenso notable en las generaciones más tardías, similar al español (ver Fina, 1996: 145). El nivel medio por cohorte también es equivalente al que encontramos en España. La homogeneidad de comportamientos con España permite sostener la existencia de una tendencia muy marcada al descenso de esta proporción (ver Fina, 1996: 144).

Sin embargo, el número de mujeres inactivas en edad de procrear supera aún ampliamente al de activas. Las que se dedican a las labores del hogar (un 36 por 100 del total) son más todavía que las ocupadas, aunque esta proporción cambia por debajo de los 35 años. En los próximos tiempos asistiremos

18 Llamamos así a aquel ingreso que induce a los miembros de la pareja a tener un hijo (ver Easterlin y otros, 1980, para una explicación pormenorizada). Puede entenderse como el conjunto mínimo de bienes y servicios a los que los progenitores deberían seguir teniendo acceso luego de su paternidad, pese a los mayores gastos ocasionados por los hijos. 
previsiblemente a un incremento de la tasa de actividad femenina, con lo cual la relación entre inactividad y fecundidad será inclusive más relevante.

En suma, hemos defendido que el coste de oportunidad del tiempo que la mujer ha de dedicar al cuidado de los hijos se ha elevado en los últimos veinte años, y que esto podría contribuir a explicar la caída de la fecundidad. Ambos fenómenos están ligados por dos variables socioeconómicas intermedias, de carácter complementario. En primer lugar, la nupcialidad. En segundo lugar, el número de hijos en el interior del matrimonio.

\section{GRÁFICO 6}

Proporción de mujeres no solteras por grupos de edad. Galicia, 1970-1991

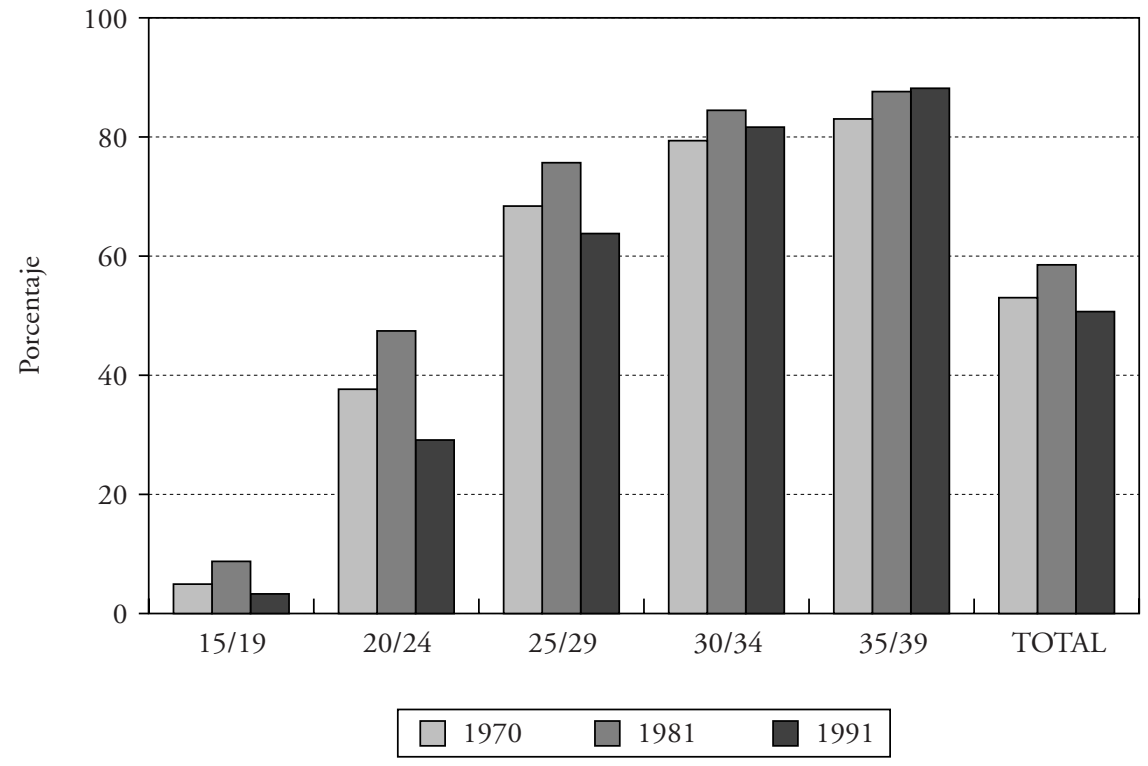

Fuentes: Censos de Población. Elaboración propia.

La primera relación encuentra un soporte empírico ambiguo. El flujo de nuevos matrimonios ha experimentado un notable agostamiento en las cuatro provincias gallegas, paralelo al de la fecundidad. En términos de stock, sin embargo, la proporción de mujeres solteras entre los 35/39 años ha disminuido ligeramente desde 1970, y aún en los años ochenta. El gráfico muestra un apreciable descenso de la nupcialidad por debajo de los 30 años, pero su mantenimiento a edades más avanzadas. No parece que este fenómeno pueda explicar, por limitaciones en la oferta, la caída de la fecundidad. El matrimonio se retrasa pero se celebra incluso en mayor medida que antes; y tiene lugar en un 
momento, en media, en el que permitiría una oferta de hijos muy superior a la que efectivamente se produce ${ }^{19}$.

La segunda relación nos parece encerrar una potencia explicativa superior. Con datos del Censo de 1991 hemos construido una medida del efecto de la inactividad de la mujer sobre la fecundidad. El cuadro recoge, para cada grupo de edad, la relación entre el número de hijos de la mujer inactiva y activa, para cada situación del marido. En todos los supuestos ${ }^{20}$ de edad o situación profesional del marido la inactividad favorece la mayor dimensión de la prole: se establece así una relación robusta entre ambos fenómenos ${ }^{21}$. Además, la diferencia tiende a decaer con la mayor edad de la mujer. No estamos en condiciones de afirmar si se trata de un efecto generacional o de la influencia de la edad de la mujer sobre el retraso de la maternidad, que se cruza con el efecto sobre la descendencia final efectiva. En cualquier caso, si observamos el valor obteni-

\section{CUADRO 2}

Número de hijos de mujeres casadas y situación profesional del marido

\begin{tabular}{|c|c|c|c|c|c|c|c|c|c|c|c|}
\hline \multirow{2}{*}{$\begin{array}{c}\text { Edad } \\
\text { de la mujer }\end{array}$} & \multicolumn{10}{|c|}{ Situación profesional del marido } & \multirow[b]{2}{*}{ Total } \\
\hline & 0 & 1 & 2 & 3 & 4 & 5 & 6 & 7 & 8 & 9 & \\
\hline $15 / 19 \ldots \ldots \ldots$ & 0,648 & 0,71 & & 0,522 & 1,314 & 0,778 & 1,096 & 0,719 & 0,872 & 0,843 & 0,824 \\
\hline $20 / 24 \ldots \ldots \ldots$ & 0,512 & 0,66 & 0,543 & 0,653 & 0,658 & 0,678 & 0,842 & 0,701 & 0,662 & 0,728 & 0,691 \\
\hline $25 / 29 \ldots \ldots \ldots$ & 0,651 & 0,64 & 0,727 & 0,679 & 0,715 & 0,725 & 0,865 & 0,77 & 0,794 & 0,713 & 0,729 \\
\hline $30 / 34 \ldots \ldots \ldots$ & 0,743 & 0,79 & 0,828 & 0,817 & 0,861 & 0,862 & 0,896 & 0,864 & 0,871 & 0,795 & 0,838 \\
\hline 35/39 .......... & 0,786 & 0,89 & 0,852 & 0,873 & 0,886 & 0,902 & 0,895 & 0,879 & 0,892 & 0,816 & 0,872 \\
\hline 40/44 .......... & 0,799 & 0,89 & 0,941 & 0,885 & 0,939 & 0,887 & 0,866 & 0,911 & 0,904 & 0,846 & 0,892 \\
\hline $45 / 49 \ldots \ldots \ldots$ & 0,875 & 0,94 & 0,904 & 0,933 & 0,912 & 0,933 & 0,867 & 0,917 & 0,876 & 0,849 & 0,894 \\
\hline TOTAL .... & 0,8 & 0,77 & 0,803 & 0,76 & 0,818 & 0,792 & 0,914 & 0,826 & 0,833 & 0,776 & 0,819 \\
\hline \multicolumn{12}{|c|}{$\begin{array}{l}0=\text { Inactivos. } \\
1=\text { Profesionales, técnicos y similares. Profesionales de las FF.AA. } \\
2 \text { = Directivos y gerentes. } \\
3=\text { Personal de servicios administrativos. } \\
4=\text { Empleados de comercio. } \\
5=\text { Hostelería y restantes servicios. } \\
6=\text { Agricultura, ganadería, silvicultura y pesca. } \\
7=\text { Construcción, industria, minería y transporte. } \\
8=\text { Peones y trabajadores no especializados. } \\
9=\text { Parados. }\end{array}$} \\
\hline \multicolumn{12}{|c|}{ FUENTE: Censo de 1991. Explotación original. Elaboración propia. } \\
\hline \multicolumn{12}{|c|}{$\begin{array}{l}19 \text { No podemos saber si esta pauta también caracteriza a las generaciones más jóvenes. } \\
{ }_{20} \text { Con excepción, en dos casos, del grupo de edad } 15 / 19 \text { años. } \\
{ }_{21} \text { Que ello suceda elimina alguna duda sobre la influencia de esta variable o su posible coli } \\
\text { alidad con otras como el nivel educativo, de ingresos, etc. }\end{array}$} \\
\hline
\end{tabular}


do para el grupo de entre 45/49 años, podemos indicar que la inactividad femenina aumenta en un 11 por 100 el número de hijos; para el grupo de 35/39 años el incremento sería del 19 por 100 .

Dos elementos adicionales refuerzan esa relación. Algunos autores señalan la posibilidad de un cambio en las preferencias de la mujer en favor del trabajo externo frente al doméstico (Keyfitz, 1987), por factores no monetarios. La expansión de las actividades de servicios - que son aquellas en las que se materializa la inserción laboral femenina- facilita la realización de un trabajo poco fatigoso, en un medio agradable que permite la relación personal. De ser así, aumenta el rendimiento no monetario del trabajo, lo que afecta al alza al coste de oportunidad de la maternidad. Por otra parte, el aumento de la probabilidad del divorcio, al reducirse sus costes monetarios y no monetarios, alienta la demanda femenina de fuentes autónomas de ingresos; en la mayor parte de los casos, tan sólo a través del trabajo externo esto es posible. Los hijos se convierten así en un bien de riesgo (Robinson, 1997), ilíquido frente a cambios drásticos en las condiciones de las familias.

Existen ajustes que reducen el grado de incompatibilidad entre actividad doméstica y fecundidad. Los cambios en la producción doméstica y la flexibilidad en la inserción laboral de la mujer son los más relevantes. La actividad externa de la mujer debería estimular una creciente participación del varón en la producción doméstica de bienes y servicios, la sustitución de bienes y servicios domésticos por bienes de mercado o la sustitución de trabajo por capital en el interior del hogar. Fina (1996: 143) concluye que globalmente se ha producido una caída muy significativa de la demanda de trabajo doméstico, debido al cambio técnico y a la sustituibilidad de bienes; pero que el hombre no participa apenas en las tareas domésticas, independientemente de que la mujer trabaje o no fuera de casa (ibidem: 155). En una casa sin niños, la doble ocupación (masculina y femenina) es soportable porque el volumen de tiempo dedicado al hogar es limitado y puede ser parcialmente sustituido gracias a la mecanización y mercantilización del mismo; esta sustitución es más fácil que ocurra si la renta de las familias es alta. Pero la maternidad y la crianza ulterior de los hijos expanden considerablemente el volumen de trabajo doméstico, cargándolo sobre las espaldas de la mujer. Existe la posibilidad de contratar servicios externos, pero el núcleo no mercantilizable tiene una cierta dimensión.

Por otra parte, las mujeres que combinan maternidad y actividad externa podrían reducir las horas dedicadas a esta última renunciando a una parte de la renta salarial. Sin embargo, el empleo femenino a tiempo parcial es escaso en España a todas las edades, en comparación con lo que sucede en la Unión Europea. El contraste es especialmente agudo con Dinamarca u Holanda. Además, la mayor parte de las trabajadoras españolas a tiempo parcial no tienen ya hijos pequeños y desempeñan jornadas reducidas (ver Fina, 1996).

Por tanto, la maternidad desequilibra el reparto del tiempo total de la pareja de ocupados en contra de la mujer, que debe realizar una doble jornada, sin apenas posibilidad de reducir la actividad exterior. La alternativa es neta: o 
doble jornada o abandono de la ocupación de mercado. Tan sólo en las parejas de mayor renta es posible utilizar una estrategia de uso intensivo del mercado, como sustitutivo del trabajo femenino en el hogar.

\subsection{Las aspiraciones de los padres y la calidad deseada para los hijos han crecido mucho más que la posibilidad de satisfacerlas}

La teoría económica de la fecundidad ha puesto de manifiesto que el precio relativo de los hijos afecta a su demanda (Becker, 1981: 132). Pero también que en la actualidad en los países desarrollados el coste del tiempo de los padres, y sobre todo de las madres, es el componente más importante del coste total. Existen otros bienes y servicios a tener en cuenta, sin embargo: servicios médicos, educativos o de cuidado de los niños; alimentación, pañales, ropa, juegos, etc. Lo sucedido con los costes de estos productos no lo conocemos con certidumbre. Una parte de los mismos es adquirida por las familias en el mercado de bienes, y podemos suponer que su coste unitario ha seguido la evolución del consumo familiar general. Otra parte es mayoritariamente provista por el sector público y financiada mediante impuestos. Cabe imaginar que para las familias de renta elevada el coste ha aumentado, dada la existencia de progresividad en el sistema fiscal; mientras que para las familias de renta baja el coste se ha reducido, beneficiándose de la existencia de transferencias implícitas en el funcionamiento de los servicios públicos. De esta manera las diferencias de fecundidad en relación con la renta deberían haberse atenuado. Pero, quizás, dada la más desfavorable evolución en el precio de los servicios, con un ligero efecto negativo sobre la fecundidad general.

Esta última reflexión conduce a preguntarse sobre los posibles efectos en la evolución de la renta sobre la demanda de hijos. Normalmente, se supone que los hijos son bienes normales y que, por lo tanto, aumenta su demanda con la renta $^{22}$. Para explicar la existencia de relaciones negativas entre renta y fecundidad se aduce la interacción entre cantidad y calidad de los hijos (Becker y Lewis, 1983; Becker, 1987). Dado que lo que demandan los padres son servicios filiales, un aumento de la calidad podría dar lugar a una mayor oferta con un número más reducido de hijos. De hecho, esto es lo que la teoría predice que ocurrirá. De esta forma se restablece la relación directa entre renta y demanda de servicios.

Existe, sin embargo, una creciente incomodidad con el concepto de calidad. Robinson (1997: 68) señala que un momento de reflexión conduce a la conclusión de que la calidad de los niños no es más que otro término para describir la tecnología de producción en el hogar para los servicios de los niños. Esa denomina-

22 Becker (1981: 139) indica que un aumento de la renta real aumenta generalmente la demanda de diferentes bienes, y los datos disponibles, de las encuestas de presupuestos familiares, demuestran que la relación entre hijos y renta no constituye una excepción. 
ción ha sido ampliada para introducir cada vez más elementos. Lo que queda es que el gasto unitario en los hijos se eleva con la renta ${ }^{23}$.

Algunos autores (ver, por ejemplo, Leibenstein, 1975), críticos con las primeras aportaciones de la nueva economía de la familia, han recordado que los padres carecen de libertad de elección sobre algunos componentes importantes del gasto por hijo: no es posible que los padres habiten en un extenso piso de la zona selecta de la ciudad y sus hijos residan en un barrio marginal. Dicho de otra forma, los padres son altruistas en relación con sus hijos, pues su función de utilidad depende positivamente del bienestar de ellos. Las normas sociales refuerzan este comportamiento y su quiebra tiene un coste para los padres egoistas.

Podríamos suponer, para hacer operativa esta relación, que los padres aspiran, al menos, a proporcionar a sus hijos las oportunidades y recursos que hacen posible la obtención de la renta que ellos desean para sí. El problema se sitúa en determinar ésta, así como las expectativas de obtención de renta familiar en el futuro. Easterlin $(1978,1987)$ o Easterlin, Pollak y Wachter (1980) han descrito un mecanismo que liga a ambas con la fecundidad. Las familias decidirán tener hijos en el momento en que las expectativas de renta permiten superar el nivel mínimo de aspiraciones de los padres en cuanto a bienes y servicios para su disfrute tanto como garantizar el bienestar mínimo de los hijos. Ese nivel mínimo depende, a su vez, del bienestar disfrutado por los jóvenes durante su adolescencia en el seno del hogar paterno. Las expectativas de renta, a su vez, se forman a partir de las tempranas experiencias en el mercado de trabajo.

Easterlin construye a partir de estos elementos un modelo de evolución cíclica y autogenerativa de la fecundidad, en la que juegan un papel central otras dos condiciones: la existencia de estabilidad en la demanda de mano de obra masculina a lo largo del tiempo, de forma que la situación en el mercado de trabajo quedase determinada por las oscilaciones de la oferta, y la segmentación del mercado de trabajo, sexual y generacionalmente: varones y mujeres no compiten; los jóvenes de sexo masculino tampoco lo hacen con los adultos del mismo sexo, al contrario de lo que sucede con las féminas.

Con estas restricciones, el número de jóvenes que integre cada generación determinará su fortuna en el mercado laboral (estabilidad, nivel salarial o rapidez de la promoción profesional). Una inserción laboral temprana y prometedora alentará la nupcialidad y la fecundidad. Pero la descendencia numerosa que este comportamiento produce mantendrá, varios lustros más tarde, una relación complicada con el empleo, debido justamente a su dimensión. Esa situación desincentivará matrimonios y nacimientos, retornando el ciclo a su punto de arranque.

Este mecanismo cíclico autogenerativo ha sido sometido a un escrutinio empírico amplio (ver Chesnais, 1983, o Rodríguez Sumaza, 1995), que confir-

${ }^{23}$ El propio Becker (1981: 130) indica que en la función de utilidad de cada familia se introduce el gasto en cada hijo, que denominamos calidad de hijos, $q$. 
ma su capacidad explicativa para Estados Unidos y otros países anglosajones. Los resultados son más contrastados para otros ámbitos. En el caso de Galicia, hemos indicado (Fernández Leiceaga, 1996) que la oferta de trabajo masculina ha sido rígida y la demanda, en cambio, ha caído sustancialmente. No parece, además, que la segmentación del mercado de trabajo sea tan acusada como en el caso estadounidense. Despojada de estas rigideces, la formulación easterliniana aún posee alguna capacidad iluminadora sobre las relaciones entre la evolución económica y la fecundidad.

El mecanismo de formación de aspiraciones antes reseñado nos parece incompleto, por cuanto no toma en consideración los efectos de la escolaridad. En la literatura sobre la inversión en capital humano éste es uno de los efectos reseñados. En el caso de Galicia, al igual que sucede en el caso español, el número medio de años de escolarización acumulados por las generaciones más jóvenes supera ampliamente al de sus mayores, como ya hemos indicado ${ }^{24}$.

Por otra parte, tiene lugar en Galicia en las dos últimas décadas una destrucción continuada del empleo. Si en 1970 se computaban 1.085 .000 empleos, quedaban tan sólo 884.000 en 1991. La destrucción de ocupación en el sector primario se ve parcialmente compensada por la creación de empleos netos en los servicios, mientras la industria (incluyendo la construcción) estabiliza sus efectivos.

Estas cifras no recogen la especificidad de la situación de los jóvenes varones, pero son suficientemente ilustrativas sobre la influencia de la evolución de la demanda de mano de obra sobre la situación del mercado de trabajo. En las fases alcistas del ciclo económico los servicios y la construcción crean puestos de trabajo en términos netos, pero la agricultura pierde aquellos abandonados por los agricultores jubilados sin sustitutos, además de los emigrados a las ciudades. En las fases depresivas los empleos terciarios crecen menos, mientras los restantes sectores pierden empleos.

La evolución de las tasas de ocupación de los varones menores de 25 años indica que las dificultades de generación de empleos alternativos a los perdidos por la modernización de la agricultura se trasladan con especial virulencia a los inicios de la vida productiva. Si los varones ocupados con menos de 25 años eran 161.000 en 1970, quedaban reducidos a sólo 70.000 en 1991, con tasas de paro persistentemente por encima del 15 por 100. Las mujeres jóvenes disponen todavía de menos oportunidades de analizar los índices de ocupación y desempleo, así como su evolución coyuntural. Además, buena parte de los empleos de que disponen los jóvenes de ambos sexos no son estables ${ }^{25}$. Los ganadores en la competencia por el empleo escaso son los adultos frente a los jóvenes, y las mujeres de mediana edad frente a sus coetáneos varones.

${ }_{24}$ Para las mujeres. Para hombres y mujeres, si el número de años de escolarización era de 3,4 para los que tenían entre 55 y 64 años, ascendía a 8,8 para los jóvenes de entre 25 y 34 (datos para 1991).

25 Más de un 90 por 100 de los contratos firmados en 1993 en Galicia eran de duración determinada, obra o servicio, eventuales o interinos (ver CGRL, 1995). Para España puede consultarse a Blanes, Gil y Pérez (1996: 169). 
El retraso y el carácter precario de la inserción en el mercado de trabajo retrasan la formación de las familias, provocando un desplazamiento en la edad medida de la nupcialidad, paternidad o maternidad ${ }^{26}$. Este fenómeno en sí mismo no daría lugar necesariamente a un descenso de la fecundidad final de las cohortes si apareciese una fecundidad tardía compensatoria, una vez que en la treintena el acceso a la estabilidad laboral fuese más masivo. Pero las dificultades aludidas afectan también a las expectativas, minorando las ganancias esperadas a lo largo de la vida activa, que se acorta (entrada más tardía) y se contempla con menor optimismo (precarización, deterioro del nivel salarial). La superior incertidumbre alimenta la resistencia a comprometerse con un bien que genera ataduras financieras a lo largo de un período cada vez más amplio, y que es totalmente ilíquido.

Conviene destacar el efecto combinado del retraso en la fecundidad y en la emancipación de los jóvenes. Con una paternidad media a los 28 años (maternidad a los 26) y una emancipación a los 25, los padres quedan libres de carga a los 53 años ( 51 para las mujeres). Pero un retraso de dos años en la paternidad y de cinco en el momento de la emancipación nos conduce hasta los 60 años (58 para las mujeres). Es posible la coincidencia con la jubilación, que se ha adelantado en la práctica en los últimos lustros. Se hace muy posible el tener hijos aún dependientes económicamente cuando la vida activa de los individuos ha terminado, lo que dificulta la acumulación de activos generadores de rentas y el ajuste en el gasto.

\subsection{También los beneficios derivados de los hijos pueden haber decrecido}

Las aportaciones de trabajo por los hijos han tenido una enorme importancia en las sociedades preindustriales. Aún en la actualidad juegan un papel no desdeñable en sociedades periféricas, tanto en la producción agrícola como en la industrial: los niños participan desde muy corta edad en la obtención de renta para la unidad familiar. Este fenómeno ha tenido en Galicia una dimensión relevante hasta la segunda mitad de este siglo, sobre todo en las explotaciones agrarias. El policultivo intensivo demandaba una gran cantidad de trabajo, máxime en ciertos períodos del año, y los niños contribuían, en ocasiones a costa de la frecuencia en la asistencia a la escuela (De Gabriel, 1990). Sin embargo, el control de la fecundidad (matrimonio tardío, celibato involuntario alto) y la persistente salida de emigrantes revelan la existencia de una oferta excesiva de mano de obra. Ya en los últimos cuarenta años se produce una rápida sustitución de trabajo por capital en el ámbito agrícola. La sanción legal y social del trabajo infantil o la universal generalización de la escolaridad obligatoria son fenómenos que dificultan la continuidad de esta práctica.

${ }^{26}$ Aunque en algunos países la relación entre fecundidad y matrimonio comienza a invertirse (ver Bourgeois-Pichat, 1987), no parece ser éste el caso de Galicia. 
Se ha reducido sustancialmente el papel de los descendientes como seguro de vejez. La rápida desagrarización de la población ocupada en los últimos treinta años (López Iglesias, 1994) ha coincidido con la progresiva universalización de un sistema público de pensiones. La urbanización afloja los nudos de la solidaridad intergeneracional y hace menguar el tamaño de la unidad familiar (Reher, 1996). La asalarización avanza, limitando el impacto de la transmisión de la propiedad para el futuro de los jóvenes. Para las generaciones más jóvenes se desvinculan paternidad y seguridad en la vejez. En los últimos años se han desarrollado instrumentos de mercado que, conjuntamente con el sistema público de reparto, impiden la dependencia monetaria de los mayores en relación con la familia. En 1991 había en Galicia 472.000 personas de más de 65 años, siendo $276.000^{27}$ el número de beneficiarios de pensiones de jubilación de la Seguridad Social, 150.000 de invalidez permanente y 125.000 de viudedad $^{28}$ (CGRL, 1995). Con todo, los descendientes aportan todavía notables servicios de cuidado y apoyo a las personas de mayor edad, sobre todo a las que padecen alguna incapacidad o están enfermas. Son las mujeres las que cumplen usualmente este papel en el seno de las familias (Rodríguez, 1994: 80). Con la elevación de la esperanza de vida aumenta la demanda de estos servicios benévolos, máxime al no haberse desarrollado una industria que pueda sustituirlos ${ }^{29}$. Tendríamos aquí un elemento favorable a la elevación de los beneficios descontados del bien hijos.

Por último, a lo largo de toda la vida de los individuos el bien hijo puede ser fuente de utilidad para los padres, aunque estos servicios tiendan a concentrarse en los primeros años de convivencia en la residencia familiar. Si aceptamos como plausible que su magnitud depende del tiempo de interacción mutua y de la calidad del hijo, cabe pensar que los padres favorezcan por esta razón la sustitución entre cantidad y calidad. No debe descartarse la existencia de economías de escala en el consumo ni la aparición de dificultades en la función de producción de hijos de calidades altas: el tiempo dedicado a los hijos (más de uno) puede permitir disfrutar conjuntamente de todos, elevando el nivel de satisfacción; la producción de un hijo de calidad alta puede exigir tener más de uno, etc.

Al tiempo, la participación femenina en el mercado laboral externo obliga a sustituir parte de las funciones del cuidado de los hijos, que tradicionalmente cumplía la madre, por servicios de mercado o ayudas familiares. Lo relevante es que las madres ocupadas tienden a acumular trabajo externo y doméstico, reduciendo el tiempo libre para dedicar a sus hijos. Por esta razón cabe imaginar también una caída del flujo de utilidad que la tenencia del hijo genera para los padres.

${ }^{27}$ Número en fuerte crecimiento: 270.000 en 1990 y 304.000 en 1995.

${ }_{28}$ No todos los beneficiarios han de tener más de 65 años.

29 En 1987 había 1,44 plazas en residencias por cada 100 ancianos (Rodríguez, 1994: 60). 


\section{REFLEXIONES FINALES}

\subsection{La homogeneización de los comportamientos reproductivos}

Una de las características que nuestra descripción de la evolución de la fecundidad ha enfatizado más es la homogeneidad geográfica del comportamiento reproductivo. La difusión de la información y la generalización de la formación media, factores que afectan a las preferencias de los individuos, reducen las diferencias socioculturales. Las distancias entre el mundo urbano y el rural, por ejemplo, son menores, tanto en términos físicos como axiológicos. Pero también influye en esa homogeneización el carácter unitario del mercado de trabajo en Galicia. Los cambios en la población activa agraria presentan un perfil anticíclico, con trasvase de activos a las áreas urbanas en los períodos expansivos (López Iglesias, 1994, 1996). Los movimientos migratorios internos a Galicia son intensos y procíclicos. Por lo tanto, las aspiraciones y las expectativas de los jóvenes tienden a coincidir en todo el territorio; estas últimas están condicionadas por la situación del mercado de trabajo urbano, en el que casi todos quieren participar. Las cifras de desempleo para los jóvenes de ambos sexos no reflejan con fidelidad la demanda potencial de puestos de trabajo urbanos. Debemos sumar una parte de los inactivos, además de los excedentes aún registrados en el empleo agrario — pese al descenso de los últimos lustros- L La recuperación de la fecundidad exigirá un redoblado esfuerzo en términos de creación de empleo. La insensibilidad de la fecundidad a las coyunturas alcistas del ciclo económico se explica al considerar que la destrucción de empleo continúa también en estas fases. Y que, en cualquier caso, los puestos de trabajo ofertados se caracterizan por su precariedad.

\subsection{Tendencia y ciclo}

En la caída de la fecundidad influyen diversos factores que afectan tanto al coste de los hijos como a los beneficios asociados a los mismos. Entre ellos hemos destacado el aumento del coste de oportunidad del trabajo femenino, medido a través de las tasas de actividad y del nivel de formación de las mujeres en edad fértil. Ambos fenómenos forman parte de un cambio sociocultural favorable a la igualdad de los sexos que consideramos felizmente irreversible. La subida en el nivel de las aspiraciones de bienestar, ligado a la profundización de la escolarización, genera un efecto similar por cuanto suponemos que los padres actúan movidos por el altruismo en relación con los hijos. El retraso en la paternidad y en la autonomización de los hijos puede llegar a trastocar el funcionamiento del ciclo vital de consumo y ahorro. Los beneficios derivados de los hijos se reducen al consumo. Los hijos serían un bien de intercambio (Gil Calvo, 1993), con difíciles sustitutos. Pero su disfrute por los padres exige un tiempo que es escaso en la familia actual. 
Esa nueva situación se configura de manera veloz y en un momento en que el mercado de trabajo se revela incapaz de garantizar a los jóvenes un nivel estable de remuneraciones que colme sus aspiraciones y permita la crianza de los hijos. Utilizamos un esquema de raigambre easterliniana, pero con modificaciones sustantivas. El nivel de la renta familiar que permite la maternidad depende menos del bienestar disfrutado en la adolescencia y más de la difusión de la formación; tampoco existen ciclos demográficos autogenerativos que configuren situaciones sucesivas de escasez y abundancia de jóvenes, cuanto factores de oferta y demanda que determinan conjuntamente el equilibrio (o desequilibrio) en el mercado de trabajo. Ni parece sensato mantener la existencia de una dualidad sexual estricta en el mundo laboral. No importa sólo la suerte de los jóvenes varones.

Estas reflexiones contienen implicaciones preocupantes. No hay solución endógena a la caída de la fecundidad, como en Easterlin, aunque una menor oferta de mano de obra, producida por una generación pequeña, pueda tener efectos positivos sobre la mejor situación de los jóvenes, alentando así la fecundidad. Pero también podría afectar a la propensión a la actividad de las mujeres (superior nivel de formación, mejores salarios y perspectivas profesionales), generando una resultante final ambigua. Los beneficios fiscales de la natalidad afectan tan sólo a los costes monetarios y de forma marginal. La comparación con otros países indica la necesidad de favorecer la inserción flexible en el mercado de trabajo, así como la importancia de crear empleo para evitar que el coste de oportunidad de la maternidad sea excesivamente elevado.

\section{BIBLIOGRAFÍA}

BECKER, G. S. (1960): «An economic analysis of fertility», en Demographic and Economic Change in Developed Countries, Princeton, National Bureau of Economic Research.

- (1987): Tratado sobre la Familia, Madrid, Alianza Universidad.

BECKER, G. S., y LEWIS, H. G. (1973): «On the interaction between quantity and quality of children", Journal of Political Economy, 82.

Becker, G. S.; Murphy, K. M., y TAMUra, R. (1990): «Human capital, fertility and economic growth", Journal of Political Economy, 98, n. 5.

Blanes, A.; GIL, F., y Pérez, J. (1996): Población y actividad en España: evolución y perspectivas, Barcelona, Colección Estudios e Informes, n. ${ }^{\circ}$, Servicios de Estudios, Caja de Ahorros y Pensiones de Barcelona.

Bourgeois-Pichat, J. (1987): "The unprecedent shortage of births in Europe», en K. DAVIS, M. S. Bernstam y R. RicARdo-Campbell, Below Replacement fertility in industrial societies, Cambridge, Cambridge University Press.

Centro de Información Estadística de Galicia (1987): A poboación de Galicia. Proxeccións, Santiago de Compostela, Xunta de Galicia.

Consello Galego de Relacións Laborais (1995): Informe sobre a situación laboral da Comunidade Autónoma Galega en 1993, Santiago de Compostela, Consello Galego de Relacións Laborais.

Chesnais, J. C. (1983): «La notion de cycle en démographie. La fécondité post transitionelle est-elle cyclique?», Population, marzo-abril. 
Davis, K.; Bernstam, R., y Ricardo-Campbell, R. (1987): Below Replacement fertility in industrial societies, Cambridge, Cambridge University Press.

DE GABRIEL, N. (1990): Leer, escribir y contar. Escolarización popular y sociedad en Galicia, 18751900, Edicións do Castro.

Del CAmpo, S. (1991): La nueva familia española, Madrid, Eudema.

Delgado Pérez, M. (1993): «Cambios en las pautas de reproducción», en L. Garrido Medina y E. Gil Calvo (dirs.), Estrategias familiares, Madrid, Alianza Universidad.

Easterlin, R. A. (1978): «The Economics and Sociology of Fertility: A Synthesis», en Ch. Tilly (ed.), Historical Studies of Changing Fertility, Princeton University Press.

- (1987): Birth and Fortune: the Impact of Numbers on Personal Welfare, Basic Books, 2. a ed.

Easterlin, R. A.; Pollak, R. A., y Wachter, M. L. (1980): «Toward a More General Economic Model of Fertility Determination: Endogenous Preferences and Natural Fertility», en R. A. Easterlin (ed.), Population and Economic Change in Developing Countries, The University Of Chicago Press.

FERNÁNDEZ MÉNDEZ DE ANDES, F. (1993): «El proceso de formación ocupacional de hombres y mujeres», en L. Garrido Medina y E. Gil Calvo (dirs.), Estrategias familiares, Madrid, Alianza Universidad.

FernándeZ Leiceaga, X. (1995): «Dinámica da poboación de Galicia», en X. Fernández Leiceaga y otros (coords.), Estudos en Homenaxe ao Profesor Xosé Manuel Beiras Torrado, Santiago de Compostela, Univ. de Santiago.

- (1996): Fecundidade e actividade en Galicia, 1970-1993, Documentos de Traballo de Economía Aplicada, Instituto de Estudos e Desenvolvimento de Galicia, Universidade de Santiago de Compostela.

FINA, L. (1996): "Trabajo en casa, fuera de casa y doble jornada», en C. Castaño y S. Palacios (eds.), Salud, Dinero y Amor (Cómo viven las mujeres españolas de hoy), Madrid, Alianza Editorial.

Gil Calvo, E. (1993): «La estrategia progenitora», en L. Garrido Medina y E. Gil Calvo (dirs.), Estrategias familiares, Madrid, Alianza Universidad.

Instituto Galego de Estadística (1987): A Poboación de Galicia. Proxeccións, Santiago de Compostela, Consellería de Economía e Facenda.

- (1991): Mercado de Traballo en Galicia, Xunta de Galicia.

- (1996): Proxección da poboación de Galicia, 1991-2026, 2 tomos, Santiago de Compostela, Xunta de Galicia.

Instituto Nacional de Estadística (1995): Evolución de la Fecundidad en España, 19701994, Subdirección General de Estadística.

Keyfitz, N. (1987): "The family that does not reproduce itself», en K. Davis, M. S. Bernstam y R. Ricardo-Campbell, Below Replacement fertility in industrial societies, Cambridge University Press.

Le Bras, H. (1991): Marianne et les lapins, París, Pluriel.

Leibenstein, H. M. (1975): "The economic theory of fertility decline», en Quarterly Journal of Economics, 89.

LÓPEZ IgLeSIAS, E. (1994): Demografía e estruturas agrárias. Análise da dinámica demográfica e das mudanças nas estruturas fundiárias da agricultura galega, 1950-1993, Univ. de Santiago, edición en microficha.

- (1996): «La dinámica reciente del sector agrario en Galicia: balance de una década de integración comunitaria", Revista Española de Economía Agraria (pendiente de publicación).

López Taboada, X. A. (1996): La población de Galicia, A Coruña, Fundación Caixa-Galicia.

Muñoz Pérez, F (1987): «Le déclin de la fécondité dans le sud de l'Europe», Population, 6.

Palafox, J.; Mora, J. G., y Pérez, F. (1995): Capital Humano, Educación y Empleo, Fundación Bancaixa.

PRESTON, S. (1987): "The decline of fertility in non european industrialized countries», en K. Davis, M. S. Bernstam y R. Ricardo-Campbell, Below Replacement fertility in industrial societies, Cambridge University Press. 
Puyol, R. (ed.) (1997): Dinámica de la población de España. Cambios demográficos en el último cuarto del siglo XX, Editorial Síntesis.

ReHer, D (1996): La familia en España. Pasado y Presente, Madrid, Alianza Editorial.

Robinson, W. C. (1997): "The Economic Theory of Fertility Over Three Decades», Population Studies, 51, 63-74.

Rodríguez, J. A. (1994): Envejecimiento y familia, Monografías, n.o 137, Madrid, Centro de Investigaciones Sociológicas.

Rodríguez SumaZA, C. (1994): Ciclos demográficos: una perspectiva socioeconómica, Valladolid, Universidad de Valladolid.

Schultz, T. P. (1987): "The value and allocation of time in high-income countries: implications for fertility", en K. Davis, M. S. Bernstam y R. Ricardo-Campbell, Below Replacement fertility in industrial societies, Cambridge, Cambridge University Press.

\begin{abstract}
In the following pages, we will tackle one of the central characteristics of Galician demography in recent years: the plummeting of fertility to a level which is well below the replacement level, with the ensuing production of increasingly less numerous generations. In the first part, we will attempt to describe this phenomenon, taking note of its rhythm, the effect of delayed motherhood and differences at provincial or urban level in relation to rural areas. In the second part, we will apply those elements of economic analysis which serve to explain this inflexion in the evolution of fertility.
\end{abstract}

